\title{
Giant peritoneal loose body: an instance of incidentaloma or warranted concern?
}

\author{
N Allopi, ${ }^{1}$ iD A Fataar, ${ }^{2}$ iD F Kimmie $^{3}$ iD \\ ${ }^{1}$ Department of General Surgery, Tygerberg Hospital, Stellenbosch University, South Africa \\ ${ }^{2}$ Karl Bremer Hospital, South Africa \\ ${ }^{3}$ Kimberley Hospital Complex, South Africa
}

Corresponding author, email: nabeelallopi@gmail.com

\begin{abstract}
Summary
In non-specific abdominal pain, cross-sectional imaging, often valued more than clinical examination in today's technologically advanced age, may reveal a large incidentaloma, posing questions regarding its relation to symptoms and the need for surgical removal. This is a situation that highlights the potential for early detection and treatment yet raises the question as to whether surgery is indeed indicated. This report relates the case of a 79-year-old male, with a longstanding history of abdominal pain, who had a giant loose peritoneal body removed. We discuss the reasons for removal and its pathogenesis.
\end{abstract}

\section{Case report}

A 79-year-old male, diagnosed with essential hypertension, was referred with a long-standing history of abdominal pain, colicky and global in radiation, accompanied by anorexia and loss of weight of approximately $5 \mathrm{~kg}$ in two years. On further inquiry, he reported no lower urinary tract or obstructive symptoms. He had had no prior hospital admission or surgical intervention. He reported no family history of cancer and is a teetotaller.

His general and systemic examination was unremarkable. In particular, he had no features of wasting or anaemia. His vital signs were normal. Abdominal examination revealed a fullness, with impression of mass, in the right lower quadrant,

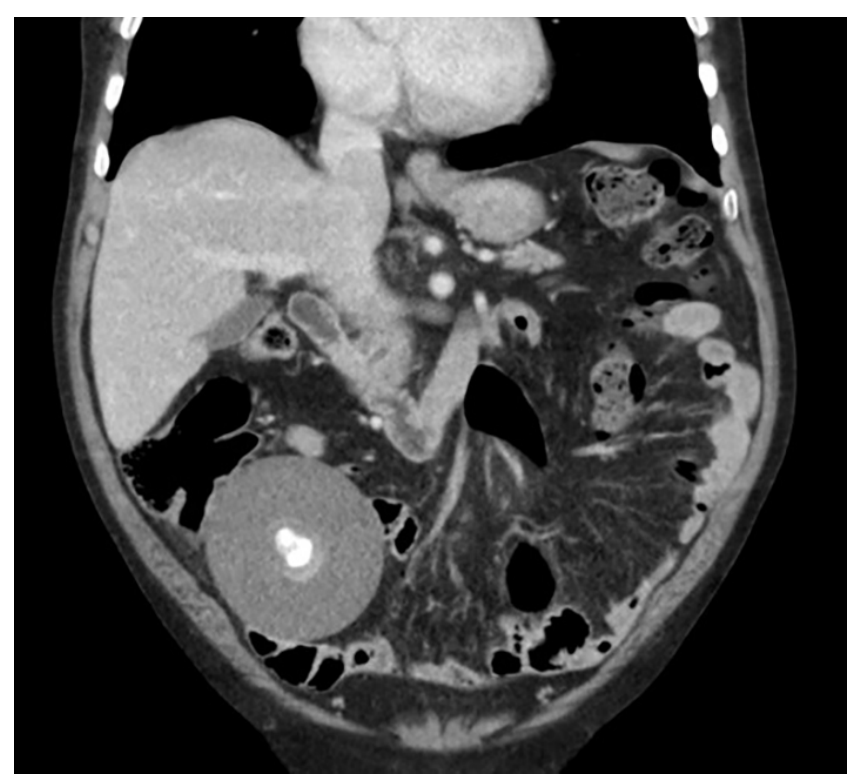

Figure 1: Preoperative CT abdomen: Coronal section showing a spherical centrally calcified large mass in the right lower quadrant but no signs of peritonism. On digital rectal examination the prostate was smooth and firm with no other abnormality.

His abdominal radiographs showed calcifications in the pelvis that were thought to be phleboliths. His baseline blood tests showed no anaemia, normal renal function and normal value tumour markers. An outpatient upper endoscopy and colonoscopy were normal. A CT abdomen was then requested, which showed a well-defined mass measuring $6.74 \times 7.9 \times 8.18 \mathrm{~cm}$, with a central area of calcification with a differential diagnosis of a teratoma or non-benign lesion (Figure 1).

Due to the uncertainty of diagnosis and suspicion of nonbenign lesion, the patient was counselled and consented

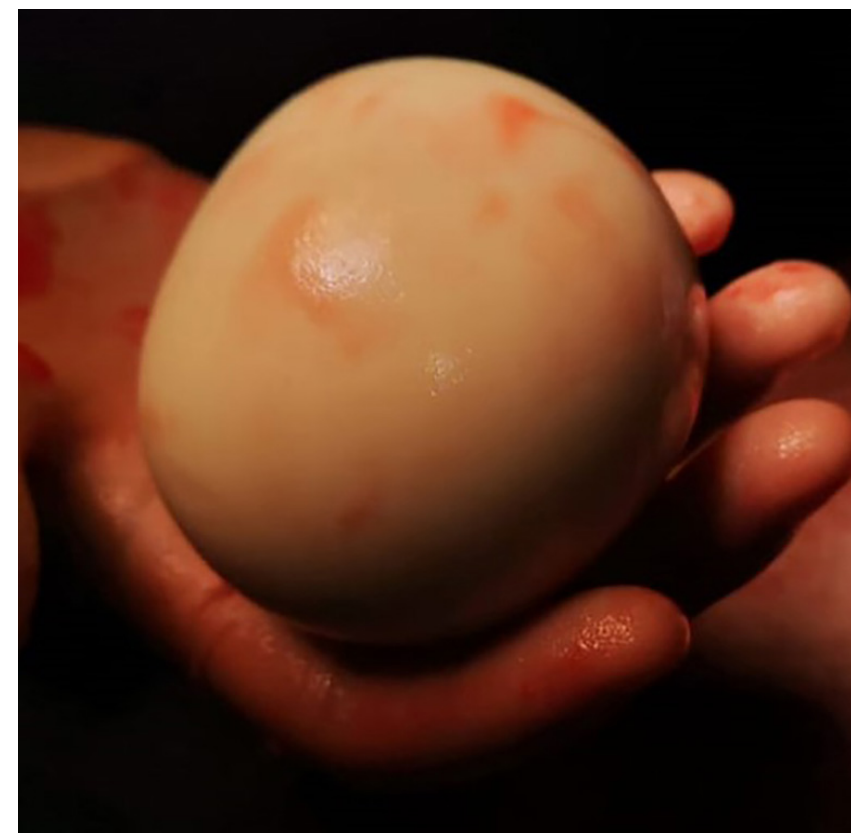

Figure 2: Specimen in hand (9 $\mathrm{cm}$ in diameter) 
for an explorative laparotomy. Intraoperative findings revealed a large, smooth, firm white ovoid mass located in the left upper quadrant, not attached to any intra-abdominal structures, with normal solid organs and hollow viscera. No intra-abdominal fluid or lymph nodes were noted. The $90 \mathrm{~mm}$ diameter $245.3 \mathrm{~g}$ mass (Figure 2) was removed and sent for histology to exclude malignancy. The histology showed a hyalinised acellular mass calcified centrally with no evidence of malignancy, in keeping with a diagnosis of a giant loose peritoneal body ${ }^{1}$ (diameter more than $5 \mathrm{~cm}$ ).

His postoperative recovery was unremarkable. He was discharged five days after surgery and at a 3-month followup visit, his abdominal symptoms were in abeyance, and he was discharged from further review.

\section{Discussion}

Giant loose peritoneal bodies are rare, poorly described entities found intra-abdominally on exploration or on $\mathrm{CT}$ scan, ${ }^{2}$ and although their exact origin is unknown, literature suggests that they form chronically from detached epiploic appendices, due to torsion and ischaemia followed by saponification, calcification, and fibrosis. ${ }^{3}$ It was also described that giant peritoneal bodies in females could arise from auto-amputated adnexa or even uterine leiomyoma or extra-uterine ectopic pregnancies. ${ }^{4}$ Literature also describes parasitised peritoneal bodies, where blood supply is derived from attached greater omentum via gastro-epiploic arteries. In some instances, they have been documented to grow larger than $5 \mathrm{~cm}$ in diameter, secondary to absorption of protein in peritoneal fluid. ${ }^{5}$

Although peritoneal loose bodies are fairly uncommon, and are often discovered incidentally, ${ }^{6}$ it should be noted that the possibility for compressive complications exists, and the differential of possible non-benign primary or metastatic lesions should be entertained. The differential diagnosis includes calcified uterine fibroids, desmoid tumours, teratomas, fecaliths or even metastasis from ovarian cancer that should be considered in the appropriate patient population, and the need for further cross-sectional imaging or intervention individualised depending on the certainty of the diagnosis. Uterine fibroids and pseudo-tumours, which are often round and located in the pelvic vicinity, demonstrate enhancement with contrast, whereas mobile loose peritoneal bodies do not. MRI has been described to further delineate these peritoneal bodies as low-intensity on $\mathrm{T} 1$ and $\mathrm{T} 2$ weighted images, aiding their diagnosis.

In this case, the peritoneal loose body had a diameter of $90 \mathrm{~mm}$, one of the largest documented in recent literature. Although his lesion had no compressive symptoms, the literature describes cases of bowel obstruction or even obstructive uropathies secondary to extraluminal compression via the mass on the bowel or ureter, requiring surgical intervention. ${ }^{7}$
Surgical patients with persistent symptomatology or concern for possible intra-abdominal malignancy should be properly evaluated ${ }^{2}$ with a comprehensive medical history, examination and relevant haematological and radiological tests. Management should be individualised on a patientto-patient basis, remembering that histological confirmation remains the definitive means of confirming a diagnosis. Hence, surgical exploration, especially if symptomatic, is a reasonable course of action.

\section{Conflict of interest}

The authors declare no conflict of interest.

\section{Funding source}

None.

\section{Ethical approval}

Ethical approval was obtained from the University of Stellenbosch Health Research Ethics Committee C20/06/016.

\section{ORCID}

N Allopi (iD https://orcid.org/0000-0002-1343-302X A Fataar (iD https://orcid.org/0000-0003-2280-132X F Kimmie (iD https://orcid.org/0000-0003-1853-0520

\section{References}

1. Zhang H, Ling Y-Z, Cui M-M. Giant peritoneal loose body in the pelvic cavity confirmed by laparoscopic exploration: a case report and review of the literature. World J Surg Oncol. 2015;13(118). https://doi.org/10.1186/s12957-015-0539-0.

2. Lu J. Will medical technology deskill doctors? J International Education Studies, 2016;9(7):130-4. Available from: http:// www.ccsenet.org/journal/index.php/es.

3. Harrigan AH. Torsion and inflammation of the appendices epiploicae. Ann Surg. 1917 Oct;66(4):467-78. https://doi org/10.1097/00000658-191710000-00014.

4. Koga K, Hiroi H, Osuga Y, et al. Autoamputated adnexa presents as a peritoneal loose body. Fertil Steril. 2010 Feb;93(3):967-8. https://doi.org/10.1016/j.fertnstert.2009.03. 038. PMID: 19394607.

5. Cojocari N, David L. Giant peritoneal loose body in a patient with end-stage renal disease. SAGE Open Medical Case Reports. January 2018. https://doi.org/10.1177/2050313X18 770936 .

6. Berland LL, Silverman SG, Gore RM, etal. Managing incidental findings on abdominal CT: white paper of the ACR incidental findings committee. J Am Coll Radiol. 2010;7(10):754-73. https://doi.org/10.1016/j.jacr.2010.06.013.

7. Abbey RK, Chandel UK. Large intraperitoneal loose body causing strangulation. J Surg Pak (Int). 2012 OctDec;17(4):172-3. 